\title{
Emergency Response Online Classes During Community Quarantine: An Exploratory Research to Philippine Private Schools
}

\author{
Ryan Lopez Race \\ Department of Education, Schools Division Office of San Pablo City, Laguna, Philippines
}

Received April 29, 2020; Revised June 4, 2020; Accepted July 1, 2020

Copyright $\bigcirc 2020$ by authors, all rights reserved. Authors agree that this article remains permanently open access under the terms of the Creative Commons Attribution License 4.0 International License

\begin{abstract}
In light of the learning continuity challenges experienced by educational institutions in the Philippines amidst the onset of the Covid-19 health crisis, the research serves to assess the conduct of emergency response online classes in a Philippine city schools division. It utilized a researcher-made instrument which assessed the profile of the respondents; their level of competence and confidence in conducting and supervising online classes; the level of preparedness of the schools; the levels of difficulty in lesson delivery and instructional supervision; and perceived advantages, disadvantages, and suggestions for improvement of online classes. Through purposive sampling, the respondents comprised 91 teachers and 24 instructional supervisors from 18 schools. Results of the study revealed that teachers and instructional supervisors needed experience and training to be able to efficiently and effectively perform their tasks in online classes; and that there were students and teachers who were not able to regularly participate in online classes due to lack of resources. Respondents also said that online classes were flexible in terms of schedule and choice of strategies, able to ensure learning continuity, were convenient, and efficient in terms of saving time, money, and effort. However, they also said that online classes had decreased participation rate, were ineffective, and had limited interaction and socialization. Conduct of training/orientation and regular practice on online classes, and ensuring needed infrastructure and resources are in place and available, respectively; as well as further research on the topic were suggested.
\end{abstract}

Keywords Online Classes, Private Schools, Community Quarantine, COVID-19, Distance Learning

\section{Introduction}

The Covid-19 pandemic is a global health emergency which involves the rapid spread of a novel coronavirus strain which has been deemed lethal for vulnerable members of the population [1]. In light of such, governments across the globe have enacted varying degrees of quarantine and lockdown procedures with the goal of mitigating the spread of the disease, thus preventing their respective healthcare systems from exceeding capacity and capability [2]. The Philippine government's response to the health crisis involved initially imposing a month-long enhanced community quarantine procedure on the island of Luzon which commenced on the 16th day of March 2020 [3]. Part of the measure included the suspension of regular face-to-face classroom sessions for all students enrolled in educational institutions covered by the quarantine declaration. As such, the measure induced varying responses from different public and private institutions ranging from adopting temporary class suspensions, granting of mass promotion for students, or transitioning into virtual classroom environments $[4,5]$. Various concerns have been raised for nearly all of the approaches taken by the different institutions. However, of particular interest for the purpose of the study at hand is with regard to the latter - online learning environments.

Online learning platforms have been established prior to the onset of the Covid-19 pandemic and have been notable for providing alternative methods for students to access learning materials outside of their physical school environment [6]. Innovation in network technology as well as economies of scale in the personal electronic device sector has enabled a wide range of educational institutions, as well as their students, to adopt online learning methods to complement traditional learning [7, 8, 9]. Educational institution stakeholders including faculty, students, and administrators cite both benefits and detriments towards 
the implementation of online learning environments. Some of the cited advantages of online learning environments have included (a) greater flexibility in adapting to individual student learning pace, (b) access to a wider range of recent and relevant learning material, and (c) increased productivity $[10,11,12]$. Despite these factors, however, not all educational institutions have adopted the technology. More so, institutions which have adopted the technology may not have necessarily implemented them for all of their educational programs [13]. Some of the issues cited as shortcomings of online-based learning included (a) the disparity in economic capabilities of students, (b) additional burden on faculty, (c) effectiveness in attention and learning retention, as well as (d) basic lack of infrastructure $[14,15,16,17]$. These issues can become more pronounced in developing countries, especially in light of those with high rates of economic inequality and poor access to network infrastructure.

Central to the study at hand is San Pablo City, a city located in the Philippine province of Laguna [18]. It has a population of around 270,000 persons, residing in an urbanized setting, and having an average income corresponding to that of a first class city [19]. The city hosts several public and private educational institutions ranging from preschools to a state university. Some of the private institutions included STI College, San Pablo Colleges, and Canossa College, all of which are located in either an urban or suburban environment [20]. These institutions have had a varying degree of adoption of online learning platforms, notably with STI College positioning itself as a technology-oriented institution [21]. This is in contrast with the public educational institutions in the city which, due to more limited funding, have not directed as many resources towards online learning platforms [22]. During the implementation of quarantine measures in the city, some private schools have adopted online learning methods, particularly emphasizing on asynchronous learning methods in order to address demands by advocacy groups regarding the difficulty in accommodating all students [23].

Considering the issues surrounding the demands entailed by the global health crises on the educational system, the researcher opted to conduct the study at hand. Specifically, the study investigated the preparedness of the schools, the competence and confidence of the teachers handling online classes, and the perceived advantages/benefits and disadvantages/challenges in online classes to serve as baseline information that policy makers and technical assistance providers may use the development of policies and provision of technical assistance that would be relevant and responsive to current and future needs.

\section{Methods}

\section{Study Design and Procedures}

The study at hand has been conducted using the mixed methods research design. With regard to data gathering, a purposive sampling technique was implemented, specifically aimed at stakeholders relevant to the study. As an exploratory research, exact sampling size was not rigorous and was subject to the limitations presented by the research locale. The study involved 18 private educational institutions which had conducted at least some form of online educational instruction. Respondents to the study included a total of ninety-one (91) class instructors who had conducted online classes, as well as twenty-four (24) instructional supervisors who had accompanied and exercised oversight during their conduct of online classes.

A link to the online survey questionnaire was distributed through relevant social media channels, specifically through the official Facebook pages and group chats of the educational institutions and respondents involved. Data collection lasted for a period of one (1) week. Respondents were informed of the purpose of the study through the questionnaire, and were assured of the privacy and security of the data that they have provided. They were also informed that participation in the study was solely voluntary. All data collection procedures conducted were performed in compliance with the provisions and Implementing Rules and Regulations of R.A. 10173, otherwise known as the Data Privacy Act of 2012.

\section{Study Questionnaire}

The primary research instrument utilized was a researcher-made questionnaire that was constructed and distributed through the Google Forms online platform. The questionnaire consists of two parts, each corresponding to the two respondent groups, instructors and supervisors. Both types of respondents were asked to provide demographic data consisting of their affiliated educational institution, position, sex, age, and duration of employment in the academe. Teachers were asked details regarding the methodology, schedule, and duration of their conduct of online classes. Specifically, teachers were asked (a) the length in days online classes are conducted, (b) number of enrolled students, (c) number of students who regularly attend online classes, (d) applications used, (e) subjects taught, (f) and grade levels taught. Teachers were further asked regarding their (a) confidence in conducting online classes, (b) and the difficulty involved in their lesson preparation. Lastly, they were asked regarding their perceptions on the advantages of/benefits from, disadvantages of/challenges, and suggestions for the improvement of the online classes. On the other hand, the instructional supervisors were also asked of (a) the number of teachers under their supervision, (b) the number of their teachers handling online classes, (c) the level of preparedness of their school in conducting online classes, (d) the difficulty levels of supervising, (d) feedback giving, and (e) giving of technical assistance during the implementation of online classes. Moreover, 
they were also asked regarding (a) their perceptions on the advantages of/benefits from and (b) disadvantages of/challenges in supervising online classes. Similar to the first group of respondents, they were also asked regarding their insight on how to improve online classes

Percentage and weighted mean were utilized to statistically analyze the results of the study. Weighted Mean range was analyzed using the Likert scale (Table 1).

Table 1. Weighted Mean Range

\begin{tabular}{|c|l|}
\hline Range & \multicolumn{1}{|c|}{ Verbal Interpretation } \\
\hline $4.20-5.00$ & $\begin{array}{l}\text { I have expertise in doing this task in an online } \\
\text { class, and can confidently assist others in doing it. }\end{array}$ \\
\hline $3.40-4.19$ & $\begin{array}{l}\text { I regularly do this task in an online class, and am } \\
\text { confident in doing it. }\end{array}$ \\
\hline $2.60-3.39$ & $\begin{array}{l}\text { I have done this task occasionally for an online } \\
\text { class but need further practice/training to be } \\
\text { confident. }\end{array}$ \\
\hline $1.80-2.59$ & $\begin{array}{l}\text { I know how to do this task but have not done this } \\
\text { before in an actual online class, and need } \\
\text { practice/training in doing it. }\end{array}$ \\
\hline $1.00-1.79$ & $\begin{array}{l}\text { I do not know how to perform this task for an } \\
\text { online class, and need practice/training in doing it. }\end{array}$ \\
\hline
\end{tabular}

Content validation of the questionnaire was done by an education program supervisor, a principal, and a master teacher. The reliability of the questionnaire was examined using Cronbach's alpha. An alpha value of more than 0.70 was considered desirable [24].

\section{Results}

The demographic composition of the sampled population stood with most of the respondents being teachers. Among these teachers, a majority of whom were identified as female; 20-30 years old; were 1-10 years in service; had conducted online classes for 11-20 days; with $66 \%$ of students regularly attending online classes; used Facebook/Messenger/Workplace; taught Math, English, and Science to Grades 11,6 and 7. On the other hand, among instructional supervisors, the results indicated that a majority were female; more than 50 years old; were 1-10 years in their current position; and with $74 \%$ of their supervised teachers conducting online classes.

Table 2 shows that most of the respondents found their respective schools to be "Somewhat prepared" in conducting online classes $(52.2 \%)$, followed closely by those which were "Not prepared" at 30.4\%. Teachers, instructional supervisors, and students had the facility and know-how for the online classes, however a number of schools did not ensure first that such requirements were in place before implementing online classes.

\section{Preparedness of the School in Conducting Online Classes}

Table 2. Percentage of Schools by Levels of Preparedness

\begin{tabular}{|l|c|}
\hline Level of Preparedness & Percentage \\
\hline 5- Very much prepared. & 0 \\
\hline 4- Quite prepared. & 8.7 \\
\hline 3- Somewhat prepared. & 52.2 \\
\hline 2- Not prepared. & 30.4 \\
\hline 1- Very much unprepared. & 8.7 \\
\hline
\end{tabular}

Competence and Confidence of Teachers in Conducting Online Classes

Table 3. Percentage of Teachers by Levels of Competence and Confidence

\begin{tabular}{|l|c|}
\hline \multicolumn{1}{|c|}{ Level of Competence and Confidence } & Percentage \\
\hline 5- I am fully competent and very much confident. & 8.60 \\
\hline 4- I am competent and quite confident. & 35.50 \\
\hline $\begin{array}{l}\text { 3- I am somewhat competent and a little bit } \\
\text { confident. }\end{array}$ & 45.20 \\
\hline 2- I am not competent and confident. & 10.80 \\
\hline $\begin{array}{l}\text { 1- I am very much incompetent and incapable of } \\
\text { conducting online classes. }\end{array}$ & 0.00 \\
\hline
\end{tabular}

Table 3 shows that most of the teachers were "Somewhat competent and a little bit confident" in conducting online classes $(45.2 \%)$, followed closely by those which were "Competent and quite confident" at $35.5 \%$. Although many of them have the necessary knowledge and skills, most still needed experience and training on online classes.

\section{Teaching-Learning Process in Online Learning}

Table 4. Average Ratings in Teaching-Learning Process

\begin{tabular}{|c|c|}
\hline Teaching-Learning Process & Percentage \\
\hline Lesson Preparation & 2.50 \\
\hline Lesson Presentation and Discussion & 2.45 \\
\hline Post-Lesson Activities & 2.59 \\
\hline Average Rating & 2.51 \\
\hline
\end{tabular}

Table 4 shows that the average rating for the teaching-learning process in online classes was 2.51 . Teachers knew how to do the tasks in lesson preparation, presentation and discussion and post-lesson activities; but have not done those before in an actual online class, and they needed practice/training in doing those.

\section{Instructional Supervision in Online Classes}

Table 5. Average Ratings in Instructional Supervision

\begin{tabular}{|c|c|}
\hline Instructional Supervision & Percentage \\
\hline Monitoring of Online Classes & 2.35 \\
\hline $\begin{array}{c}\text { Feedback-giving and Providing Technical } \\
\text { Assistance to Teachers in an Online Class }\end{array}$ & 2.39 \\
\hline Average Rating & 2.37 \\
\hline
\end{tabular}


Table 5 shows that the average rating for the instructional supervision in online classes was 2.37. Instructional supervisors knew how to do the tasks in instructional supervision; but have not done those before in an actual online class, and they needed practice/training in doing those.

\section{Perceived Advantages of Online Classes}

Table 6. Percentages of Perceived Advantages of Online Classes

\begin{tabular}{|c|c|}
\hline Advantage & Percentage \\
\hline $\begin{array}{c}\text { Flexible } \\
\text { (In schedule and strategy) }\end{array}$ & 20.87 \\
\hline Ensures Learning Continuity & 18.26 \\
\hline $\begin{array}{c}\text { Efficient } \\
\text { (Saves time, money and effort) }\end{array}$ & 14.78 \\
\hline Convenient & 12.17 \\
\hline None & 7.83 \\
\hline Promotes Use of Technology & 6.96 \\
\hline Promotes Independent Learning & 6.09 \\
\hline $\begin{array}{c}\text { Safe } \\
\text { (Practices home quarantine and social } \\
\text { distancing) }\end{array}$ & 5.22 \\
\hline Increased Parental Involvement & 4.35 \\
\hline $\begin{array}{c}\text { Accessible } \\
\text { (To those with strong internet connection, and } \\
\text { with needed equipment/gadgets) }\end{array}$ & 2.61 \\
\hline Increased Class Participation & 0.87 \\
\hline
\end{tabular}

Table 6 shows that flexibility, ensuring learning continuity, efficiency, and convenience were the top perceived advantages of online classes at $20.87 \%, 18.26 \%$, $14.78 \%$, and $12.17 \%$, respectively. Other perceived advantages were promotion of technology and independent learning, safety, increased parental involvement, accessibility, and increased participation.

\section{Perceived Disadvantages of Online Classes}

Table 7. Percentages of Perceived Disadvantages of Online Classes

\begin{tabular}{|c|c|}
\hline Disadvantage & Percentage \\
\hline $\begin{array}{c}\text { (Due to poor/lack of internet connection, lack of } \\
\text { needed equipment/gadgets) }\end{array}$ & 52.63 \\
\hline $\begin{array}{c}\text { Ineffective } \\
\text { (Due to lack of adequate training and learning } \\
\text { materials) }\end{array}$ & 15.04 \\
\hline $\begin{array}{c}\text { Limited Interaction and Socialization } \\
\text { (Student-student \& Student-Teacher) }\end{array}$ & 11.28 \\
\hline Difficulty in Class Management & 5.26 \\
\hline Prone to Distractions at Home & 5.26 \\
\hline Prone to Cheating & 4.51 \\
\hline Limited Time for Discussion & 3.01 \\
\hline Difficulty in Assessment & 1.50 \\
\hline Lack of Experiential Learning & 0.75 \\
\hline Difficulty in File Management & 0.75 \\
\hline
\end{tabular}

Table 7 shows that decreased participation rate, ineffectiveness, and limitation in interaction and socialization were the top perceived disadvantages of online classes at $52.63 \%, 15.04 \%$, and $11.28 \%$, respectively. Other perceived disadvantages were difficulty in class management, being prone to distractions at home and to cheating, limited discussion time, difficulty in assessment, lack of experiential learning, and difficulty in file management.

\section{Suggestions for Improvement of Online Classes}

Table 8. Percentages of Suggestions for Improvement of Online Classes

\begin{tabular}{|l|c|}
\hline \multicolumn{1}{|c|}{ Suggestion } & Percentage \\
\hline $\begin{array}{l}\text { Ensure Needed Infrastructure are in place and } \\
\text { Needed Resources (internet connection, } \\
\text { equipment, gadgets, learning materials) are } \\
\text { available. }\end{array}$ & 57.65 \\
\hline $\begin{array}{l}\text { Provide Training/Orientation to Instructional } \\
\text { Supervisors, Teachers, Parents, Students. }\end{array}$ & 37.65 \\
\hline $\begin{array}{l}\text { Provide Alternative Learning Delivery Modes for } \\
\text { those who will not be able to participate in online } \\
\text { classes. }\end{array}$ & 3.53 \\
\hline $\begin{array}{l}\text { Develop Guidelines on the Implementation of } \\
\text { Online Classes. }\end{array}$ & 1.18 \\
\hline
\end{tabular}

Table 8 shows that ensuring needed infrastructure and resources are in place and available; provision of training/orientation to instructional supervisors, teachers, parents, and students; provision of alternative learning delivery modes for those who are unable to participate in online classes; and development guidelines on the implementation of online classes were the suggested ways to improve online classes at $57.65 \%, 37.65 \%, 3.53 \%$, and $1.18 \%$, respectively.

\section{Discussion}

The circumstances surrounding the current implementation of online learning platforms in the Philippines are extraordinary and have caused significant challenges in attaining the goals of the educational system. Consistent with initial research, developing countries such as the Philippines are more susceptible to the issues surrounding the implementation of remote learning options if transition systems and mechanisms are not planned or well implemented [14, 17]. As such, it becomes essential to continually assess the state of online class implementation in the country in order to serve as a reference for policy makers and other stakeholders to modify and improve its implementation, thus optimizing it towards achieving the objectives of the country's educational system.

The study at hand revealed that stakeholders perceived that schools were only somewhat prepared in implementing online classes. This perception has been linked with a perceived failure of schools to ensure that necessary facilities and resources were available for implementation. This, however, is not unlikely when 
considering the economic state of the schools' locale, which when compared with those from the National Capital Region, deviates significantly and leaves schools in San Pablo City with much less resources to dedicate to transitioning to online learning platforms [19]. Similarly, considering that some of the schools covered in the study have not had much integration with online learning platforms prior to the onset of the health crisis, their stakeholders were most likely inadequately prepared as well, possessing electronic devices which may not necessarily be optimized for online learning [9, 14]. Depending on the individual needs of each educational institution, as determined by the needs of their stakeholders as well as their resource allocation, policy makers and administrators have the option of either implementing commercially-available e-learning platforms, or adopting their own internal system for their students and faculty $[6$, 7].

Teachers were found to be somewhat competent and a little bit confident in conducting online classes. Similarly, while both teachers and their instructional supervisors had the competence to perform their tasks in the teaching-learning process and instructional supervision, respectively, they have not yet had enough experience to conduct the same tasks within the domain of an online learning platform. This entails the need for additional training with regard to technology and infrastructure usage, adaptation to challenges in inciting class participation, and ensuring paced learning for all student stakeholders $[10,11$, 12]. One of the ways in which this may be achieved would be through building upon the opportunity presented by the rate of smartphone adoption by users in the Philippines [25, 26]. With a rising likelihood of smartphone ownership in the country, policy makers and administrators may take advantage of such in order to integrate students' and the faculty's personal devices into the online learning system adopted by the educational institution $[6,7]$.

The respondents' perceived advantages and disadvantages of online learning platforms were consistent with findings from initial research. Respondents perceived flexibility, ensuring learning continuity, efficiency, and convenience as advantages of adopting online learning solutions $[10,11,12]$. On the other hand, respondents perceived decreased participation rates, ineffectiveness, and limitation in interaction and socialization as disadvantages of online learning solutions [14, 15, 16, 17]. In order to address such, respondents stated that there was a need to improve network infrastructure and resources in order to accommodate the logistical requirements of conducting online classes. This is consistent with the fundamental principles in practicing online learning [6]. Additionally, technical literacy training was determined by respondents as a potential solution towards addressing the level of preparedness of instructors and supervisors had in adopting online education techniques. Lastly, respondents have indicated that there must be alternative measures in place in order to accommodate students and faculty members who may not have access to online learning platforms. This is consistent with the issue surrounding economic disparity among students, as well as critiques presented by advocacy groups regarding ensuring that all students have the same level of opportunity [14, 23]. Overall, respondents believe that taking the issues that arose in the conduct of online classes into consideration, policy makers may develop better and more organized guidelines regarding the implementation of online classes.

\section{Limitations}

While the research has been conducted according to established research procedure, it was subject to varying degrees of limitation brought about by its coverage, circumstantial obstacles, and its applicability to the broad field of education. Firstly, the research only focused on program implementation, and did not take into consideration the specific effects of online classes to learners, teachers, and instructional supervisors. Secondly, challenges surrounding the implemented quarantine measures and limitation in terms of internet broadband connectivity of the general populace have led to a lower response rate than expected. No alternative data collection method was conducted for those without access to internet connectivity, potentially opening the research to skewed data as a result of the phenomenon of "survivorship bias." Lastly, the results gathered from the research may be applicable only to schools which have similar circumstances and levels of preparedness in the implementation of their classes.

\section{Future Research}

Taking into consideration the limitations aforementioned, as well as the general needs of the academe, the researcher recommends further studies to be conducted with regard to similar or related topics. Specifically, the researcher recommends studies to be conducted on other locales, especially those in rural or less developed areas in order to assess the impacts of online learning to their capability to deliver learning objectives for their students. Furthermore, once circumstances allow for such, research may also be conducted on respondents who do not have access to the data collection method utilized in the study at hand.

\section{Conclusions}

The study revealed multiple areas of shortcoming and room for improvement with regard to San Pablo City private schools' implementation of their respective online learning programs. Significant issues arose with regard to the levels of preparedness of instructors and supervisors in transitioning to and handling the conduct of online classes. Furthermore, it was found that there is a need for the 
respective educational institutions to increase their own levels of preparedness, particularly with regard to establishing a system for online learning, as well as allocating the necessary resources in order to conduct such. Recommendations were formulated according to the responses of the sampled population, as well as accompanying research material. Such recommendations ranged from practical means such as procuring integrated online learning systems and infrastructure, to addressing specific lapses in technical skill by conducting technical literacy training in order to aid instructors and their respective supervisors.

\section{Acknowledgments}

The researcher acknowledges the Grace of the Lord Almighty, which had enabled him to pursue and accomplish the objectives of this research. He also expresses great gratitude to the top management personnel of the Schools Division of San Pablo City for their support which included guidance and input contributing to the necessary data and references for the conduct of the study. Lastly, the researcher thanks all of the participants of the study for allocating their time and resources towards its completion.

\section{REFERENCES}

[1] Cascella, M., Rajnik, M., Cuomo, A., Dulebohn, S. C., \& Di Napoli, R. (2020). Features, evaluation and treatment coronavirus (COVID-19). In Statpearls [internet]. StatPearls Publishing.

[2] Walker, P., Whittaker, C., Watson, O., Baguelin, M., Ainslie, K., Bhatia, S., ... \& Cucunuba Perez, Z. (2020). Report 12: The global impact of COVID-19 and strategies for mitigation and suppression.

[3] Cuaton, G., Caluza, L. J., \& Neo, J. F. (2020). COVID-19 Health Response from January to April 2020 in the Philippines: A Topic Modeling Analysis using Latent Dirichlet Allocation Algorithm. Available at SSRN 3590910.

[4] Toquero, C. M. (2020). Challenges and Opportunities for Higher Education amid the COVID-19 Pandemic: The Philippine Context. Pedagogical Research, 5(4).

[5] Pelmin, M. (2020). Readings on Coronavirus Disease (COVID-19) and the Higher Education Institution (HEIs) Emergency Preparedness in the Philippines. Available at SSRN 3573896.

[6] Anderson, T. (Ed.). (2008). The theory and practice of online learning. Athabasca University Press.

[7] Van Schewick, B. (2012). Internet architecture and innovation. Mit Press.

[8] Woyke, E. (2014). The Smartphone: Anatomy of an industry.
The new press.

[9] Kim, D., Chun, H., \& Lee, H. (2014). Determining the factors that influence college students' adoption of smartphones. Journal of the Association for Information Science and Technology, 65(3), 578-588.

[10] Song, L., \& Hill, J. R. (2007). A conceptual model for understanding self-directed learning in online environments. Journal of Interactive Online Learning, 6(1), 27-42.

[11] Means, B., Toyama, Y., Murphy, R., Bakia, M., \& Jones, K. (2009). Evaluation of evidence-based practices in online learning: A meta-analysis and review of online learning studies.

[12] Meyer, K. A., \& McNeal, L. (2011). How online faculty improve student learning productivity. Journal of Asynchronous Learning Networks, 15(3), 37-53.

[13] Walser, N. (2011). Spotlight on Technology in Education. No. 7 in the Harvard Education Letter Spotlight Series. Harvard Education Press. 8 Story Street First Floor, Cambridge, MA 02138.

[14] Pruet, P., Ang, C. S., \& Farzin, D. (2016). Understanding tablet computer usage among primary school students in underdeveloped areas: Students' technology experience, learning styles and attitudes. Computers in Human Behavior, $55,1131-1144$.

[15] Burden, K. J., \& Kearney, M. (2017). Investigating and critiquing teacher educators' mobile learning practices. Interactive Technology and Smart Education.

[16] Chen, C. M., \& Wu, C. H. (2015). Effects of different video lecture types on sustained attention, emotion, cognitive load, and learning performance. Computers \& Education, 80, $108-121$

[17] Winseck, D. (2017). The geopolitical economy of the global internet infrastructure. Journal of Information Policy, 7, 228-267.

[18] Philippine Statistics Authority. (2016). Province of Laguna. Retrieved June 02, 2020, from https://psa.gov.ph/classificati on/psgc/?q=psgc/citimuni/043400000

[19] Philippine Statistics Authority. (2016). PSA Releases the Municipal and City Poverty Estimates. Retrieved June 02, 2020, from https://psa.gov.ph/sites/default/files/City\%20an d\%20Municipal-level\%20Small\%20Area\%20Poverty $\% 20 \mathrm{E}$ stimates_\%202009\%2C\%202012\%20and\%202015_0.xlsx

[20] Private Schools in San Pablo CIty, Laguna. (n.d.). Retrieved June 02, 2020, from https://san-pablo-city.infoisinfo-ph.co $\mathrm{m} / \mathrm{search} /$ private-school

[21] STI College. (n.d.). Retrieved June 02, 2020, from https://www.sti.edu/

[22] Bernardo, A. B., Ganotice, F. A., \& King, R. B. (2015). Motivation gap and achievement gap between public and private high schools in the Philippines. The Asia-Pacific Education Researcher, 24(4), 657-667.

[23] Bagayas, S. (2020, March 23). Students urge suspension of online classes during coronavirus lockdown. Retrieved June 02, 2020, fromhttps://www.rappler.com/nation/255504-stu dents-urge-suspension-online-classes-coronavirus-lockdow $\mathrm{n}$

[24] Worley, W. L., \& Tesdell, L. S. (2009). Instructor time and 
effort in online and face-to-face teaching: Lessons learned. IEEE Transactions on Professional Communication., 52(2), 138

[25] Poushter, J. (2016). Smartphone ownership and internet usage continues to climb in emerging economies. Pew Research Center, 22, 1-44.

[26] Kim, J. S. The Integrated Model of Smartphone Adoption in Asia Pacific Market. 